\title{
Berberine and Metformin in the Treatment of Type 2 Diabetes Mellitus: A Systemic Review and Meta-Analysis of Randomized Clinical Trials
}

\author{
Li Wang1, Donglan Liu², Guohong Wei ${ }^{3}$, Hui Ge ${ }^{1^{*}}$ \\ ${ }^{1}$ Department of Healthcare, The First Affiliated Hospital, Sun Yat-sen University, Guangzhou, China \\ ${ }^{2}$ Outpatient Clinic of Internal Medicine Department, The First Affiliated Hospital, Sun Yat-sen University, Guangzhou, China \\ ${ }^{3}$ Department of Endocrinology, The First Affiliated Hospital, Sun Yat-sen University, Guangzhou, China \\ Email: ^gehui2009gh@126.com
}

How to cite this paper: Wang, L., Liu, D.L., Wei, G.H. and Ge, H. (2021) Berberine and Metformin in the Treatment of Type 2 Diabetes Mellitus: A Systemic Review and Meta-Analysis of Randomized Clinical Trials. Health, 13, 1314-1329. https://doi.org/10.4236/health.2021.1311096

Received: October 19, 2021

Accepted: November 21, 2021

Published: November 24, 2021

Copyright $\odot 2021$ by author(s) and Scientific Research Publishing Inc. This work is licensed under the Creative Commons Attribution International License (CC BY 4.0).

http://creativecommons.org/licenses/by/4.0/

\begin{abstract}
Objective: To assess the effects of berberine and metformin on glucose in patients with type 2 diabets mellitus (T2DM) with a systematic review and meta-analysis. Methods: The databases including PubMed, Excerpta Medica Database (EMBase), Cochrane Library, Chinese National Knowledge Infrastructure database (CNKI), WanFang, the Chinese Scientific and Technical Journals database (VIP), China Doctor Dissertation Full-text Database (CDFD) and China Master Dissertation Full-text Database (CMFD) from the inception to April 2021 in Chinese or English language were searched. Randomized controlled trials (RCTs) of berberine only or combined with metformin versus metformin were included. Data extraction and paper quality assessment were conducted according to the Cochrane Handbook. RevMan 5.4 was used for the meta-analysis. Results: A total of thirteen studies were included, covering 1173 participants. The clinical heterogeneity of the included trials was relatively high. The methodological quality of most trials was generally low with bias in terms of random sequence generation, allocation concealment, blinding method, outcome data and selective reporting. Interventions were divided into two subgroups for analysis. Meta-analysis suggested that there was no statistical significance in the hypoglycemic effect between berberine and metformin for T2DM. However, berberine combined with metformin could reduce fasting plasma glucose (FPG) $[M D=-1.49,95 \%$ CI $(-2.22,-0.76), P$ $<0.0001]$, 2-hour postprandial blood glucose (2hPG) $[M D=-1.89,95 \% \mathrm{CI}$ $(-2.94,-0.84), P=0.0004]$, glycosylated hemoglobin Alc (HbA1c) $[M D=$ $-0.65,95 \%$ CI $(-0.91,-0.40), P<0.00001]$ and homeostasis model assess-
\end{abstract}


ment of insulin resistance (HOMA-IR) $[M D=-0.53,95 \%$ CI $(-1.03,-0.03)$, $P=0.04$ ] levels significantly compared with metformin group. No severe adverse effects were reported in all trials. Conclusions: The hypoglycemic effect of berberine alone is not better than metformin. But berberine combined with metformin has good efficacy and safety in the treatment of T2DM. The current clinical studies are low in methodology and reporting quality, which needs to be further proved by more high quality, large sample size and multi-center RCTs.

\section{Keywords}

Berberine, Metformin, Type 2 Diabetes Mellitus, Efficacy, Safety, Meta-Analysis

\section{Introduction}

The incidence of type 2 diabetes mellitus (T2DM) is increasing rapidly worldwide. Thirty years ago, T2DM was a fairly rare occurrence in adults and was almost undocumented in children [1]. In 2010, 285 million people with T2DM comprised approximately $90 \%$ of diabetes worldwide [2]. The results of Chronic Disease and the risk factors in China in 2013 showed that the prevalence rate of diabetes in adult group was $10.4 \%$ and increased to $11.2 \%$ in 2017 [3]. The global prevalence of diabetes is estimated to rise to 592 million by the year 2035, and there will be more than 500 million patients with T2DM [2].

Metformin, a derivative of biguanide, is one of the most commonly used drugs to treat T2DM, and it has been used for nearly one century [4]. Guanidine was found to have anti-diabetic properties in animals in 1918. But unfortunately, it was toxic in clinical trials [5]. This prompted scientists to find safer substitutions. In the 1920, metformin (1, 1-dimethyl biguanide hydrochloride) was synthesized. Since then, metformin became the first choice to treat T2DM due to its remarkable ability to decrease plasma glucose levels [6]. In recent years, many additional unexpected but effective roles of metformin were found. Studies showed that metformin exerts a strong effect on numerous cancer [7], cardiavascular disease (CVD) [8], liver disease [9], obesity [10] and renal disease [11]. Sole medication or combination therapy with other drugs has shown to be effective to treat different diseases.

Berberine (BBR, molecular formula: $\mathrm{C}_{20} \mathrm{H}_{19} \mathrm{NO}_{5}$, molecular weight: 353.36), an isoquinoline alkaloid originally isolated from the Chinese herb Coptis chinensis (Huanglian), is one of the main components of $R$. coptidis [12]. Berberine has been used in traditional Chinese, Indian, and middle-eastern folk medicine for more than 400 years. Its chemical structure as a quaternary base is quite different from other commonly used hypoglycemic agents, such as sulfonylureas, biguanides, thiazolidinediones, or acarbose. Recent studies have demonstrated that berberine has remarkable effects as an anti-hyperglycemic and anti-hyperlipidemic 
and it reduces weight gain in T2DM [13] [14] [15]. In addition, the beneficial effects of berberine on cardiovascular, liver, and renal disease have been demonstrated in both pre-clinical and clinical research [16] [17] [18].

Berberine and metformin share many features in actions despite different structure and both could be excellent drugs in treating T2DM. Meanwhile, berberine can improve the intestinal intolerance of metformin [19]. The combination of the two drugs may bring better hypoglycemic effect. This research used the Cochrane systematic evaluation method and evaluated the efficacy and safety of berberine and metformin in treating T2DM in RCTs. It is important clinical significance for the development of diabetes therapy.

\section{Materials and Methods}

\subsection{Inclusion Criteria}

Studies were included if they fulfilled the following criteria: Randomized controlled trials (RCTs), irrespective of blinding; People with T2DM, preexisting or newly diagnosed; for the types of interventions, treatments with berberine alone or combined with metformin compared with metformin. Literature is either Chinese or English litersture. Some studies contained multiple groups and each group was considered as a separate study in the analysis. Studies were only included if the intervention was given for at least 8 weeks. To be consistent with changes in diagnostic criteria of T2DM through the years, the diagnosis should has been established using the diagnostic criteria valid at the time of the beginning of the trial [20]. The diagnosis criteria include WHO 1999 [21] and CDS 2013 [22].

The primary outcomes consisted of fasting plasma glucose levels (FPG), 2-hour postprandial plasma glucose (2hPG), glycosylated hemoglobin levels A1c (HbA1c). The secondary outcomes consisted of homeostasis model assessment of insulin resistance (HOMA-IR) and adverse effects.

\subsection{Exclusion Criteria}

The exclusion criteria were non-randominzed controlled trials and quasi-randomized controlled trials; abstracts or comments from conference papers; animal studies and obvious duplicate studies.

\subsection{Search Strategy}

We searched the following electronic databases for the identification of trials: PubMed, Excerpta Medica Database (EMBase), Cochrane Library, Chinese National Knowledge Infrastructure database (CNKI), WanFang, the Chinese Scientific and Technical Journals database (VIP), China Doctor Dissertation Full-text Database (CDFD) and China Master Dissertation Full-text Database (CMFD) from the inception to April 2021 in Chinese or English language. The following search terms were used: ["Berberine" or "Huangliansu" or "Xiaopojian"] and ["metformin" or "dimethyldiguanide"] and ["type 2 diabetes mellitus" or "T2DM" 
or "non-insulin-dependent diabetes mellitus"]. In addition, the reference lists from the articles were manually searched for further studies.

\subsection{Data Extraction}

Literature selecting: read the article title and abstract, eliminated the studies not meeting the inclusion/exclusion criteria. Two reviewers independently assessed trials for inclusion in the review. They extracted data concerning details of the sample size, interventions, duration of treatment, age and outcomes by using a standard Microsoft Excel (Microsoft Corporation, office 2016) file. Any disagreements were resolved by consensus, or if required by a third reviewer.

\subsection{Quality Assessment}

Bias is a systematic error other than random error that can lead to differences between research results and the real situation. There are many sources of bias, including selection bias, performance bias, detection bias, attrition bias and reporting bias. The quality of the included trials was assessed using the Cochrane risk bias tools (Review Mamager 5.4 provided by the Cochrane Collaboration) [23]. The criterias include random sequence generation (selection bias), allocation concealment (selection bias), blinding of participants and personnel (performance bias), blinding of outcome assessment (detection bias), incomplete outcome data (attrition bias), selective reporting (reporting bias) and other bias. We made judgement on each of these criterias relating to the risk of bias: low, high, or unclear (indicating unclear or unknown risk of bias).

\subsection{Statistical Methods}

We used the RevMan 5.4 meta-analysis sofeware to summarize the effects of berberine. Categorical variables used the odds ratio (OR) and continuous variables used the mean differences (MD) as analysis statistics. 95\% confidence interval $(95 \% \mathrm{CI})$ was used as effective size for the combined analysis. The clinical and methodological heterogeneity of the included studies was evaluated with $X^{2}$ test and $P$ test. The different berberine and/or metformin intervention metheods were used for sensitivity subgroup analysis. Reporting bias was explored through funnel plot analysis when the number of included trials exceeded ten. A fixedeffect model was used when the studies in the subgroup were sufficiently similar $(P<50 \%, P>0.10)$. Otherwise, a random-effect model was used. When $P<$ 0.05 , it indicated that there was a significant difference between the two groups. Interval estimation and hypothesis test results were shown in the forest plot.

\section{Results}

\subsection{Literature Search Results}

The primary searches identified a total of 552 references. 137 articles were screened after 415 duplicates of the same articles were removed. According to the inclusion criteria, 124 records were excluded because they were not RCTs, animal 
studies, not set control group reasonable, reviews or comments. Finally, thirteen studies met the eligibility criteria and were included in the systematic review and meta-analysis. The flowchart of study search results was displayed in Figure 1.

\subsection{Characteristics of the Included Studies}

The thirteen studies, including eleven in Chinese and two in English, were published in 2008-2020. One study [27] was performed as multicenter and the other studies as single center. All studies were originated from the mainland of China. Tow studies adopted three-armed group design including berberine, berberine combined with metformin, and metformin [25] [29]. The other studies adopted two-armed paralled group design. According to the inclusion criteria, the two studies were analyzed as four trials [25] [29]. A total of 1173 T2DM patients were enrolled. Among them, 599 were in the experimental group and 574 in the control. All articles describled medication on the basis of diet and exercise. See Table 1 .

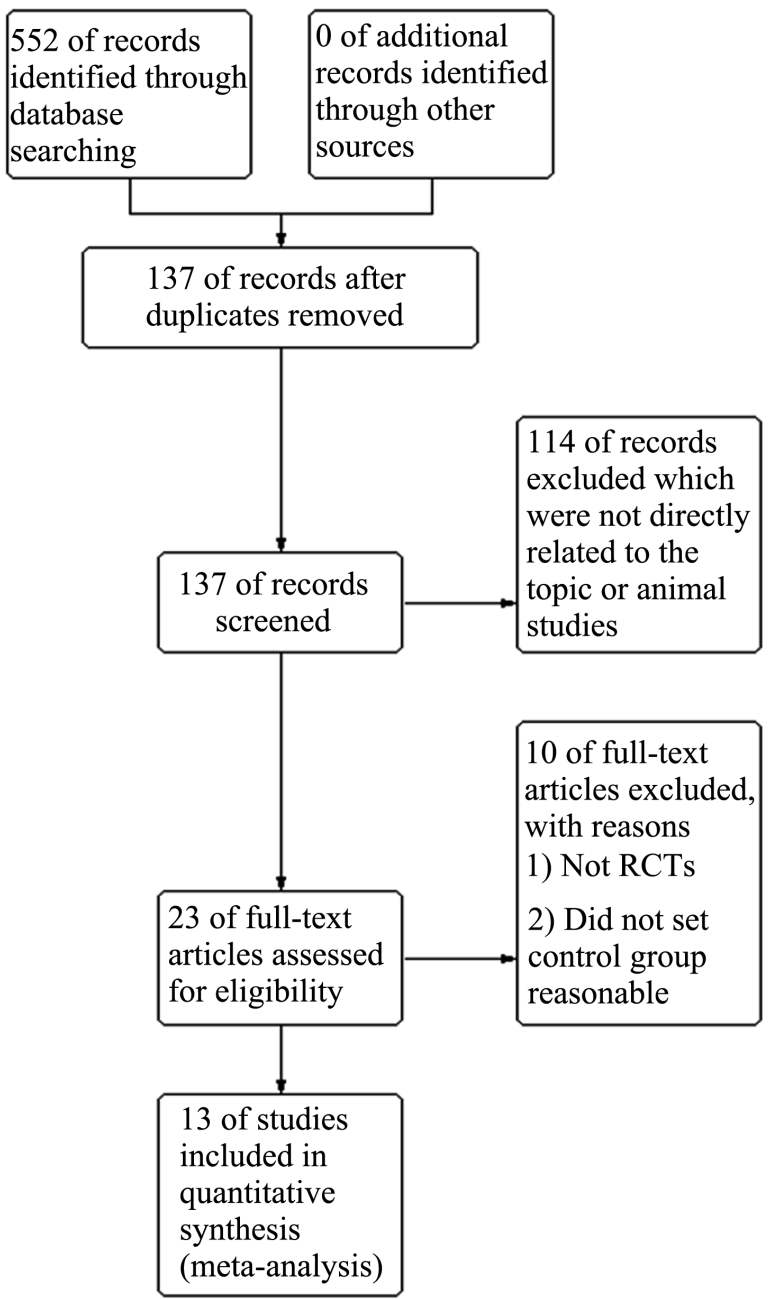

Figure 1. Flow chart of the strategy used for the selection of studies used in the metaanalysis. 
Table 1. Characteristics of the included trials.

\begin{tabular}{|c|c|c|c|c|c|c|c|}
\hline \multirow{2}{*}{ Study } & \multirow{2}{*}{$\begin{array}{c}\text { Sample size } \\
\text { (Experimental/ } \\
\text { control) }\end{array}$} & \multicolumn{2}{|c|}{ Intervation } & \multirow{2}{*}{ Duration } & \multicolumn{2}{|c|}{ Mean age (year) } & \multirow{2}{*}{ Outcomes } \\
\hline & & Experimental & control & & Expemental & control & \\
\hline Jun Y, 2008 [24] & $15 / 16$ & $\operatorname{BBR}(0.5$, tid $)$ & $\operatorname{Met}(0.5$, tid $)$ & $13 \mathrm{~W}$ & \multicolumn{2}{|c|}{$25-75$} & (1)(2)(3)(5) \\
\hline $\begin{array}{c}\text { Xue SX, } \\
2012 \text { (1) [25] }\end{array}$ & $42 / 45$ & $\operatorname{BBR}(0.3$, tid $)$ & Met $(0.75 / \mathrm{d})$ & $12 \mathrm{~W}$ & \multicolumn{2}{|c|}{$54 \pm 11$} & (1)(2)(3) \\
\hline $\begin{array}{l}\text { Zhang YD, } \\
2012[26]\end{array}$ & $38 / 38$ & $\operatorname{BBR}(0.5-0.8, \mathrm{tid})$ & $\operatorname{Met}(0.5, \mathrm{tid})$ & $3 \mathrm{M}$ & - & - & (1)(2)(3)(5) \\
\hline Hao Z, 2010 [27] & $50 / 26$ & $\operatorname{BBR}(1.0 / d)$ & $\operatorname{Met}(1.5 / \mathrm{d})$ & $2 \mathrm{M}$ & $57 \pm 8$ & $56 \pm 11$ & (1)(2)(5) \\
\hline Cao Y, 2007 [28] & $30 / 30$ & $\operatorname{BBR}(0.5, \mathrm{tid})$ & Met $(0.5$, tid $)$ & $3 \mathrm{M}$ & $55.3 \pm 11.5$ & $53.6 \pm 12.9$ & (1)(2)(3) \\
\hline $\begin{array}{c}\text { Li ML, } \\
2008 \text { (1) [29] }\end{array}$ & $17 / 17$ & $\operatorname{BBR}(0.3$, tid $)$ & Met $(0.5, \mathrm{tid})$ & $12 \mathrm{~W}$ & \multicolumn{2}{|c|}{$61 \pm 12$} & (1)(2)(5) \\
\hline $\begin{array}{c}\text { Liu ZM, } 2013 \\
{[30]}\end{array}$ & $36 / 32$ & $\begin{array}{l}\text { BBR }(0.3-0.5, \text { tid }) \\
+ \text { Met }(0.5, \text { bid or } \\
\text { increase slowly } \\
\text { to } 2.0 / d)\end{array}$ & $\begin{array}{c}\text { Met }(0.5, \text { bid } \\
\text { or increase } \\
\text { slowly to } 2.0 / d)\end{array}$ & $16 \mathrm{~W}$ & $56.5 \pm 7.2$ & $47.5 \pm 6.5$ & (1)(2)(3)(5) \\
\hline $\begin{array}{c}\text { Xue SX, } \\
2012(2)[25]\end{array}$ & $44 / 45$ & $\begin{array}{c}\operatorname{BBR}(0.45 / \mathrm{d})+\mathrm{Met} \\
(0.75 / \mathrm{d})\end{array}$ & Met $(0.75 / \mathrm{d})$ & $12 \mathrm{~W}$ & - & - & (1)(2)(3) \\
\hline $\begin{array}{l}\text { Zhou Q, } \\
2012[31]\end{array}$ & $46 / 46$ & $\begin{array}{c}\operatorname{BBR}(0.2, \text { tid })+\text { Met } \\
(0.5, \text { tid })\end{array}$ & Met $(0.5$, tid $)$ & $12 \mathrm{~W}$ & \multicolumn{2}{|c|}{$44.67 \pm 8.52$} & (1)(2) \\
\hline $\begin{array}{l}\text { Zhan HJ, } \\
2015[32]\end{array}$ & $40 / 40$ & $\begin{array}{c}\operatorname{BBR}(0.2, \text { tid })+\text { Met } \\
(0.5, \text { tid })\end{array}$ & $\operatorname{Met}(0.5$, tid $)$ & $3 \mathrm{M}$ & \multicolumn{2}{|c|}{$51.6 \pm 3.8$} & (1)(2)(3)(4) \\
\hline $\begin{array}{l}\text { Lu LM, } \\
2013[33]\end{array}$ & $27 / 26$ & $\begin{array}{c}\operatorname{BBR}(0.3, \text { tid })+\text { Met } \\
(0.5, \text { bid })\end{array}$ & Met $(0.5$, bid $)$ & $2 \mathrm{M}$ & $68(43-79)$ & $70(46-82)$ & (1)(2)(3) \\
\hline $\begin{array}{l}\text { Jiang WL, } \\
2019[34]\end{array}$ & $51 / 51$ & $\begin{array}{c}\operatorname{BBR}(0.3, \text { tid })+\text { Met } \\
(0.5, \text { tid })\end{array}$ & $\operatorname{Met}(0.5, \mathrm{tid})$ & $12 \mathrm{~W}$ & $63.19 \pm 4.82$ & $62.76 \pm 4.59$ & (1)(2)(3)(5) \\
\hline $\begin{array}{l}\text { Yang X, } \\
2020[35]\end{array}$ & $96 / 96$ & $\begin{array}{c}\operatorname{BBR}(0.3, \text { tid })+\text { Met } \\
(0.5-1.0, \text { bid })\end{array}$ & $\begin{array}{c}\text { Met } \\
(0.5-1.0, \text { bid })\end{array}$ & $3 \mathrm{M}$ & $49.9 \pm 7.8$ & $49.7 \pm 7.4$ & (1)(2)(3) \\
\hline $\begin{array}{c}\text { Li ML, } \\
2008 \text { (2) [29] }\end{array}$ & $18 / 17$ & $\begin{array}{c}\operatorname{BBR}(0.3, \text { tid })+\text { Met } \\
(0.5, \text { tid })\end{array}$ & $\operatorname{Met}(0.5$, tid $)$ & $12 \mathrm{~W}$ & \multicolumn{2}{|c|}{$61 \pm 12$} & (1)(2) \\
\hline $\begin{array}{l}\text { Dong KL, } \\
2017[36]\end{array}$ & $49 / 49$ & $\begin{array}{c}\operatorname{BBR}(0.3, \mathrm{tid})+\mathrm{Met} \\
(0.5, \mathrm{tid})\end{array}$ & $\operatorname{Met}(0.5, \mathrm{tid})$ & $12 \mathrm{~W}$ & $51.34 \pm 4.43$ & $52.23 \pm 4.41$ & (1)(2)(3) \\
\hline
\end{tabular}

Note: -, no record; BBR, berberine; Met, metformin; W, week; M, month; (1) FPG; (2) 2hPG; (3) HbAlc; (4) HOMA-IR; (5) adverse effects.

\subsection{Risk of Bias in Included Studies}

We used RevMan 5.4 to assess the risk of bias in the included thirteen studies according to the Cochrane Manual [23]. Most of the included trials were of poor quality. All the studies mentioned random assignment of participants. But only one study [35] described random sequence generation methods, such as random number tables. There was insufficient information to determine whether the randomizations were carried out correctly in the rest of the studies. All the trials were not describle the allocation concealment and blinding. Three studies [24] 
[27] [28] reported the number of withdrawals and drop-outs in each group. Four studies [24] [33] [34] [36] were not reported selectively. Two studies [27] [29] mentioned other biases. None of them reported the reseach plan and sample size estimation method. The risk of bias in included studies was shown in Figure 2.

\subsection{Outcome Indicators}

Thirteen studies (fifteen trials) were included in the study. The control groups were all metformin treatment. Considering that the intervention measures of berberine treatment were different, the influencing factors such as drug dosage and course of treatment could not be combined and analyzed. Therefore, the intervention types of experimental and control group were analyzed in subgroups, which were divided into berberine vs. metformin and berberine combined with metformin (berberine plus metformin) vs. metformin.

\subsubsection{Efficacy of Berberine and Metformin Treatment on FPG}

There were six trials compared the effect of berberine vs. metformin on FPG and nine trials for berberine combined with metformin vs. metformin. Due to high heterogenerty, $P>50 \%$, random-effect (RE) model was used for the analysis. Subgroup analysis showed that berberine combined with metformin significantly reduced FPG leval compared with metformin group, $[\mathrm{MD}=-1.49,95 \% \mathrm{CI}$ $(-2.22,-0.76), P<0.0001]$. There was no significant difference between berberine and metformin, [MD $=0.13,95 \% \mathrm{CI}(-0.27,0.54), P=0.53]$. See Figure 3.

\subsubsection{Efficacy of Berberine and Metformin Treatment on $2 \mathrm{hPG}$}

There were five trials compared the effect of berberine vs. metformin on $2 \mathrm{hPG}$ and nine trials for berberine combined with metformin vs. metformin. Due to high heterogenerty, $P>50 \%$, random-effect (RE) model was used for the analysis. Subgroup analysis showed that berberine combined with metformin significantly reduced $2 \mathrm{hPG}$ leval compared with metformin group, [MD $=-1.89,95 \%$ CI $(-2.94,-0.84), P=0.0004]$. There was no significant difference between berberine and metformin, $[\mathrm{MD}=0.11,95 \% \mathrm{CI}(-1.38,1.60), P=0.88]$. See Figure 4.

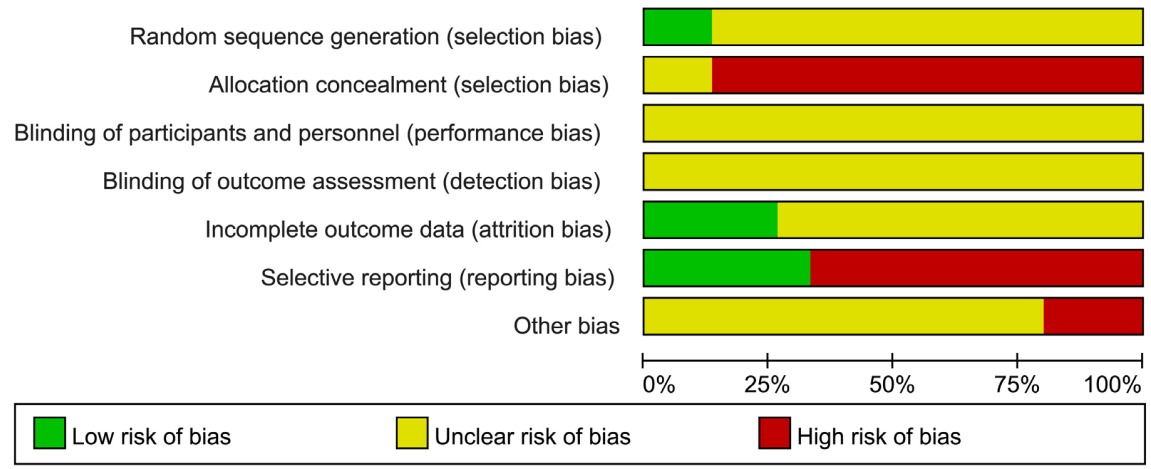

Figure 2. Risk of bias accessed using RevMan 5.4 according to the guidance in the Cochrane Handbook. Green represents low risk of bias, yellow represents unclear risk of bias, and red represents high risk of bias. 


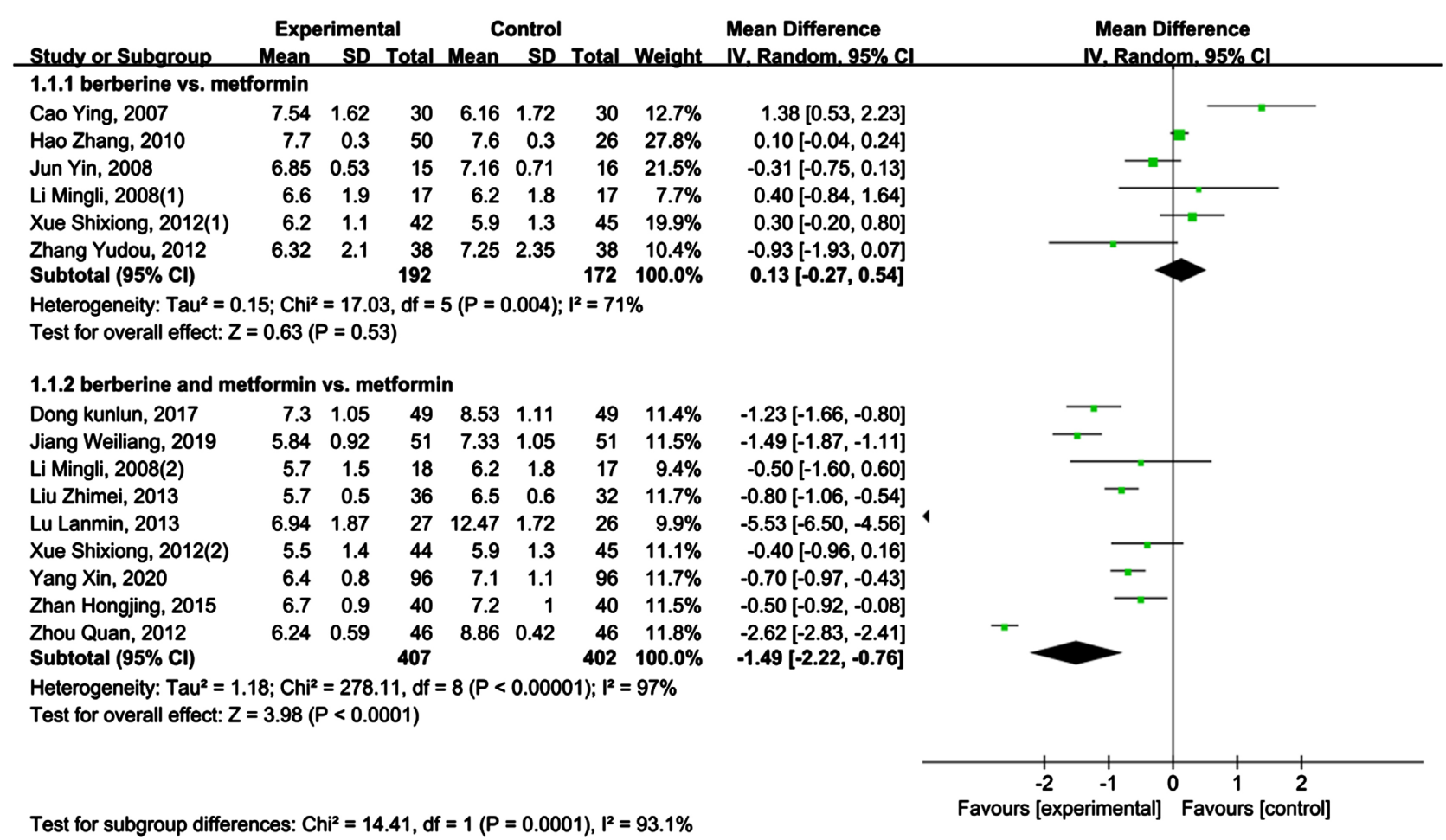

Figure 3. Forest plot of outcome measure FPG.

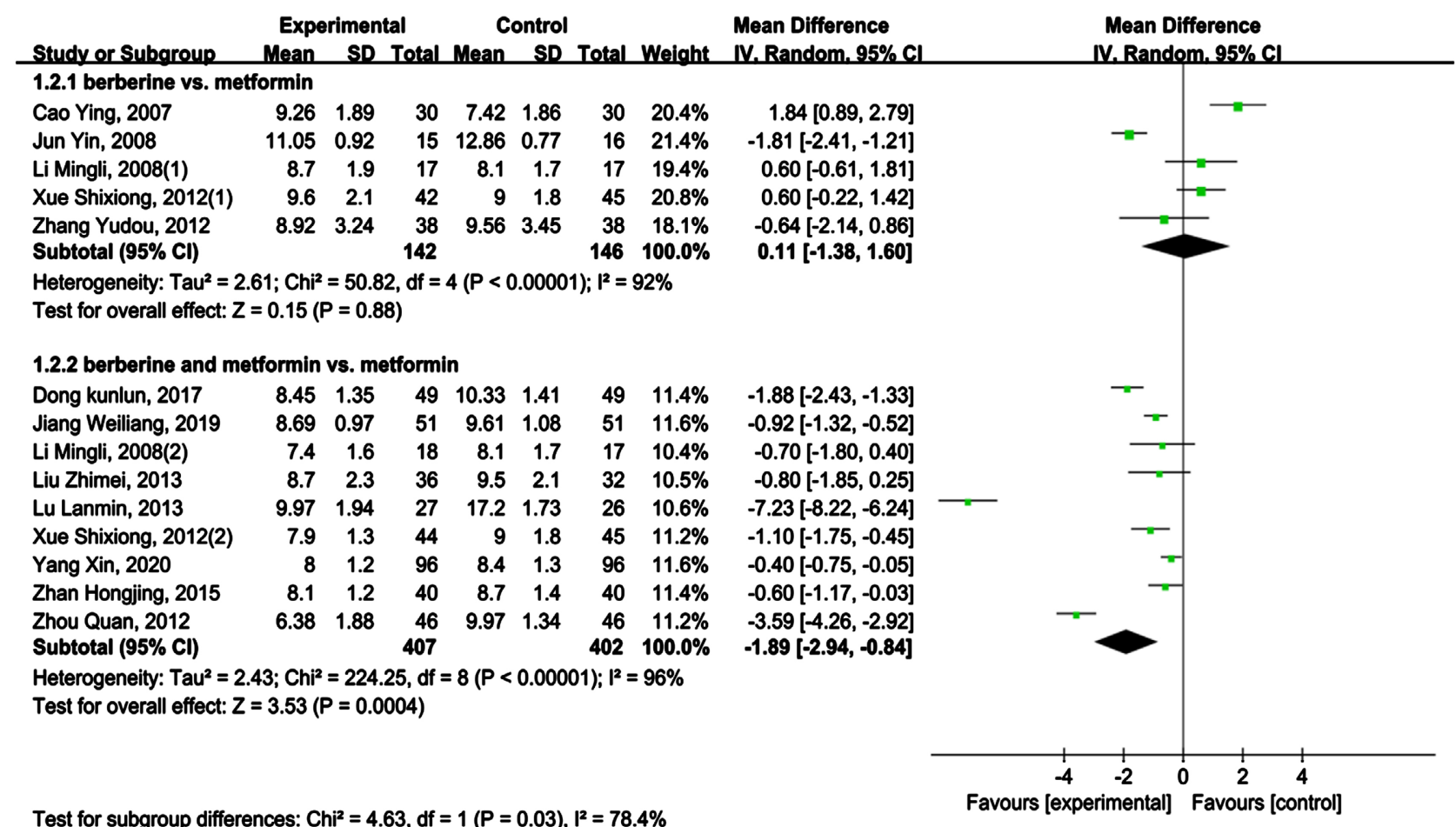

Figure 4. Forest plot of outcome measure 2hPG.

\subsubsection{Efficacy of Berberine and Metformin Treatment on HbA1c}

There were five trials compared the effect of berberine vs. metformin on HbAlc and seven trials for berberine combined with metformin vs. metformin. Due to 
high heterogenerty, $P>50 \%$, random-effect (RE) model was used for the analysis. Subgroup analysis showed that berberine combined with metformin significantly reduced $\mathrm{HbAlc}$ leval compared with metformin group, [MD $=-0.65,95 \%$ CI $(-0.91,-0.40), P<0.00001]$. There was no significant difference between berberine and metformin, $[\mathrm{MD}=-0.17,95 \% \mathrm{CI}(-0.49,0.16), P=0.31]$. See Figure 5 .

\subsubsection{Efficacy of Berberine and Metformin Treatment on HOMA-IR}

Only one trial compared the effect of berberine and metformin vs. metformin on HOMA-IR. There was sigificant difference between the two groups, [MD $=-0.53$, 95\% CI $(-1.03,-0.03), P=0.04]$. No trial compared the effect of berberine vs. metformin on HOMA-IR. See Figure 6.

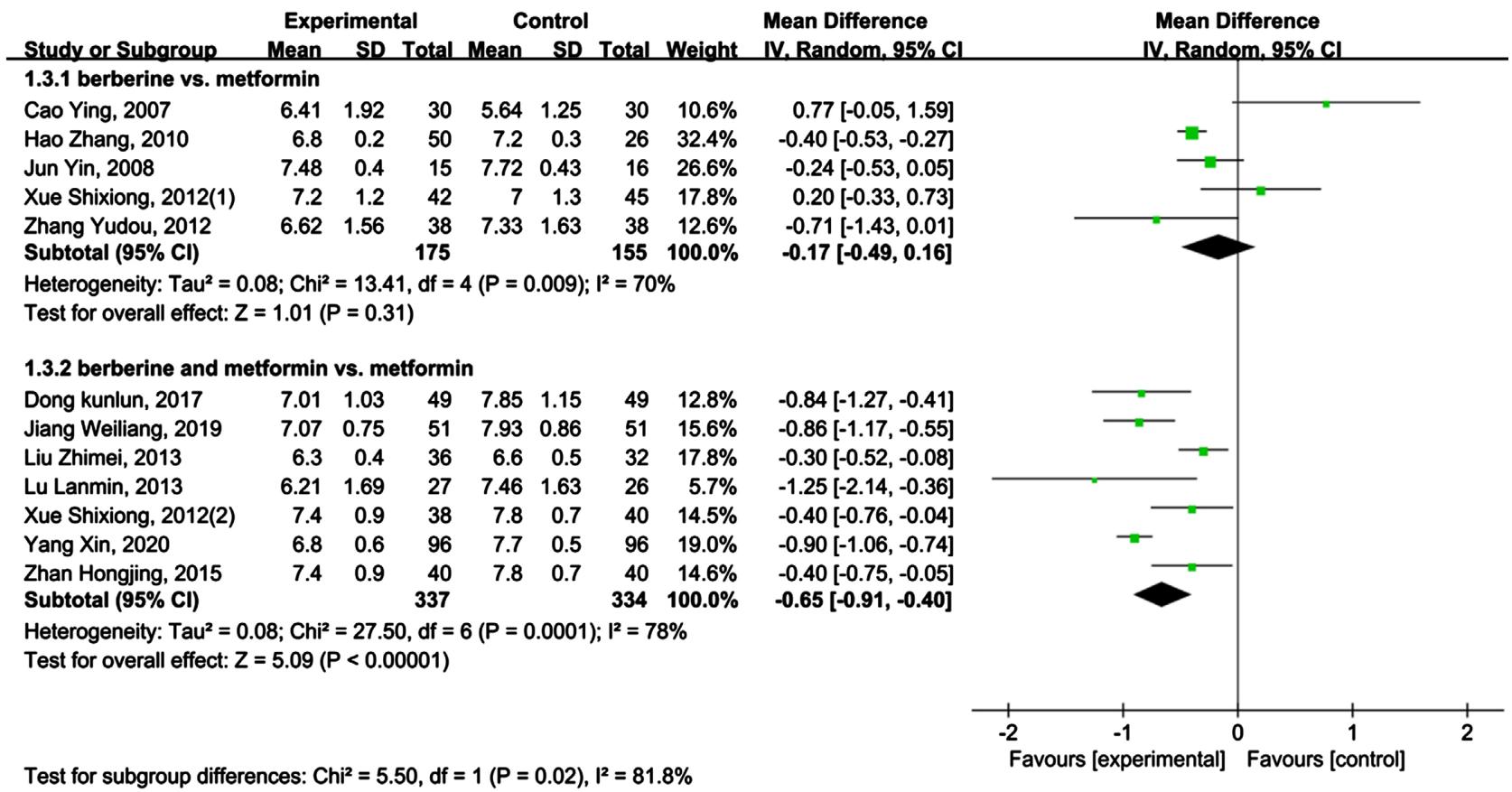

Figure 5. Forest plot of outcome measure HbA1c.

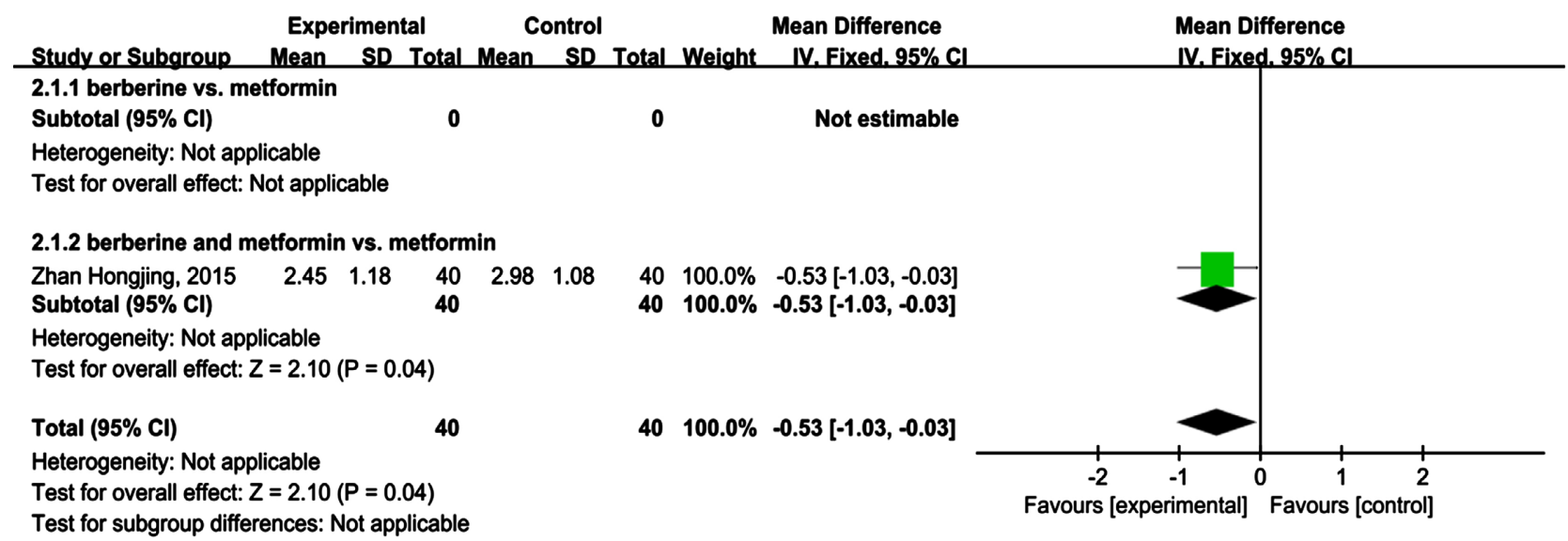

Figure 6. Forest plot of outcome measure HOMA-IR. 


\subsubsection{Efficacy of Berberine and Metformin Treatment on Adverse Effects} Six trials reported the number of adverse effects and the other trials only stated a slight adverse effects of berberine without clear data. Due to high heterogenerty, $P^{P}>50 \%$, random-effect (RE) model was used for the analysis. Subgroup analysis showed that there was no significant difference between berberine and metformin, [MD $=0.27,95 \% \mathrm{CI}(0.04,1.84), P=0.18]$. The other subgroup, the adverse effects rate of berberine combined with metformin was significantly decreased, $[\mathrm{MD}=0.41,95 \% \mathrm{CI}(0.18,0.95), P=0.04]$, compared with metformin group. All reported events were mild, including constipation, diarrhea, nausea and abdominal distension. No serious adverse effects were reported. See Figure 7.

\subsection{Sensitivity Analysis}

Sensitivity analysis was carried out by eliminating literature one by one. FPG and $\mathrm{HbAlc}$ for the subgroup of berberine vs. metformin, were significantly affected by the article, Cao Y [28]. The results changed from $[P=0.53, P=71 \%$, $\mathrm{MD}=-0.13,95 \% \mathrm{CI}(-0.27,0.54)]$ and $[P=0.31, P=70 \%, \mathrm{MD}=-0.17,95 \% \mathrm{CI}$ $(-0.49,0.16)]$ to $[P=0.89, P=50 \%, \mathrm{MD}=-0.02,95 \% \mathrm{CI}(-0.33,0.29)]$ and $[P=$ $0.02, P=52 \%, \mathrm{MD}=-0.29,95 \% \mathrm{CI}(-0.53,-0.05)]$, respectively. After excluding the article, berberine could significantly reduce HbA1c of T2DM compared with metformin group. The adverse effect in the subgroup changed from $[P=0.18, P$ $=61 \%, \mathrm{OR}=0.27,95 \% \mathrm{CI}(0.04,1.84)]$ to $[P=0.003, P=0 \%, \mathrm{OR}=0.12,95 \% \mathrm{CI}$ $(0.03,0.49)]$ after removing the article, Jun $\mathrm{Y}[24]$. There was no significant change in sensitivity analysis for the subgroup of berberine combined with metformin vs. metformin.

\subsection{Publication Bias Analysis}

A funnel plot was made for FPG in the fifteen trials included. Visual inspection

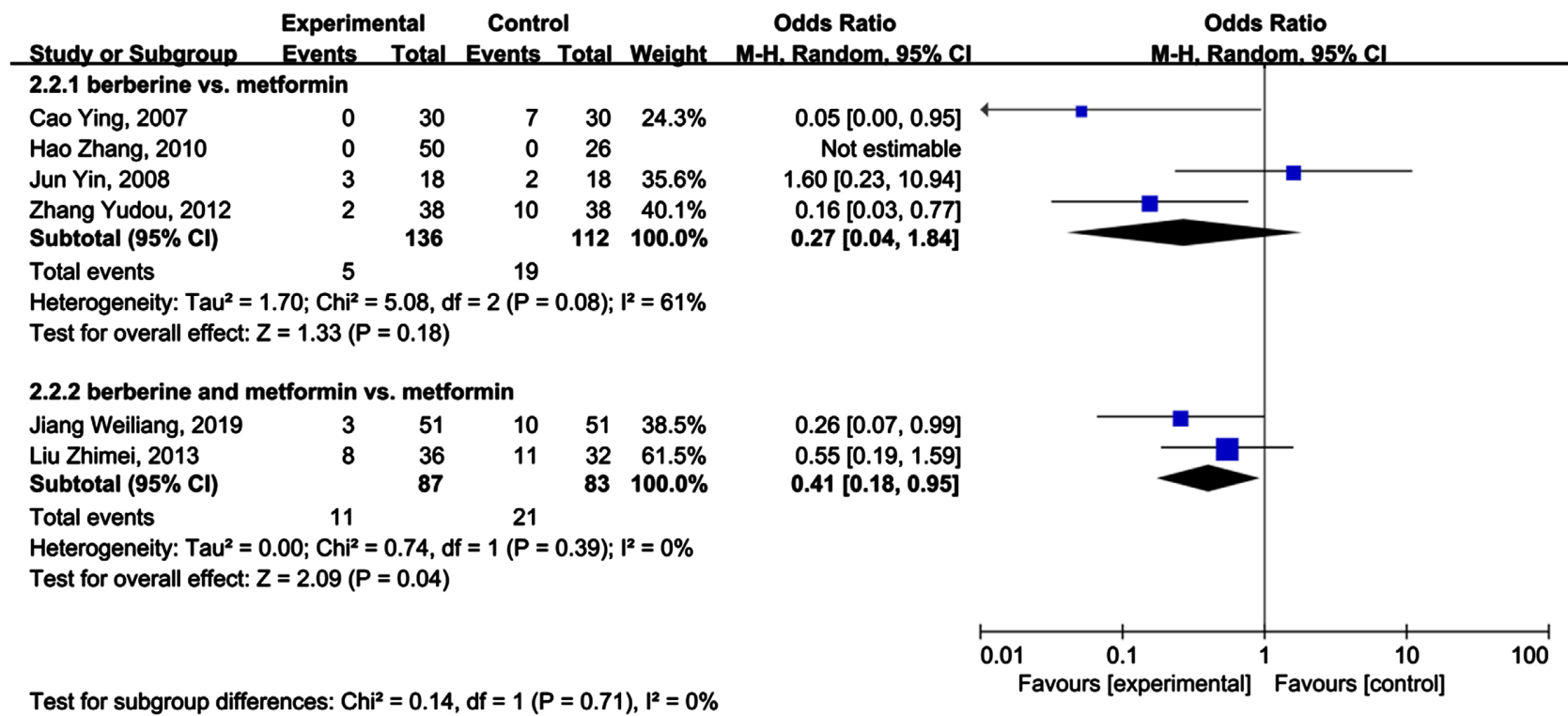

Figure 7. Forest plot of adverse effects. 
showed obvious asymmtetry between the left and right sides of the symmetry axis, suggesting potential publication bias. See Figure 8.

\section{Discussion}

\subsection{Summary of Evidence}

Fifteen RCTs with 1173 participants evaluating the efficacy and safety of berberine and metformin in patients with T2DM were eligible and included. Metaanalysis showed that berberine combined with metformin remarkably lowered plasma concentrations of FPG [MD $=-1.49,95 \% \mathrm{CI}(-2.22,-0.76), P<0.0001]$, 2hPG [MD $=-1.89,95 \%$ CI $(-2.94,-0.84), P=0.0004]$, HbAlc $[M D=-0.65$, $95 \%$ CI $(-0.91,-0.40), P<0.00001]$ and HOMA-IR $[M D=-0.53,95 \%$ CI $(-1.03$, $-0.03), P=0.04]$. But berberine monotherapy was not superior to metformin in the hypoglycemic effect. The incidence of adverse events did not differ between berberine and metformin group. However, berberine combined with metformin significantly reduced the incidence of adverse events, $[M D=0.41,95 \% \mathrm{CI}(0.18$, $0.95), P=0.04$ ], in other subgroup. It is possible that berberine may prevent metformin-associated lactic acidosis in treatment of diabetes [37]. In a world, the adverse effects were commonly gastrointestinal discomforts including constipation, diarrhea, nausea and abdominal distension. No serious adverse effects from berberine and metformin were reported. These results indicate that berberine and metformin treatment is effective and safe for treating T2DM.

\subsection{Comparison with Previous Studies}

Our meta-anlysis has some strength in comparison with previous systematic

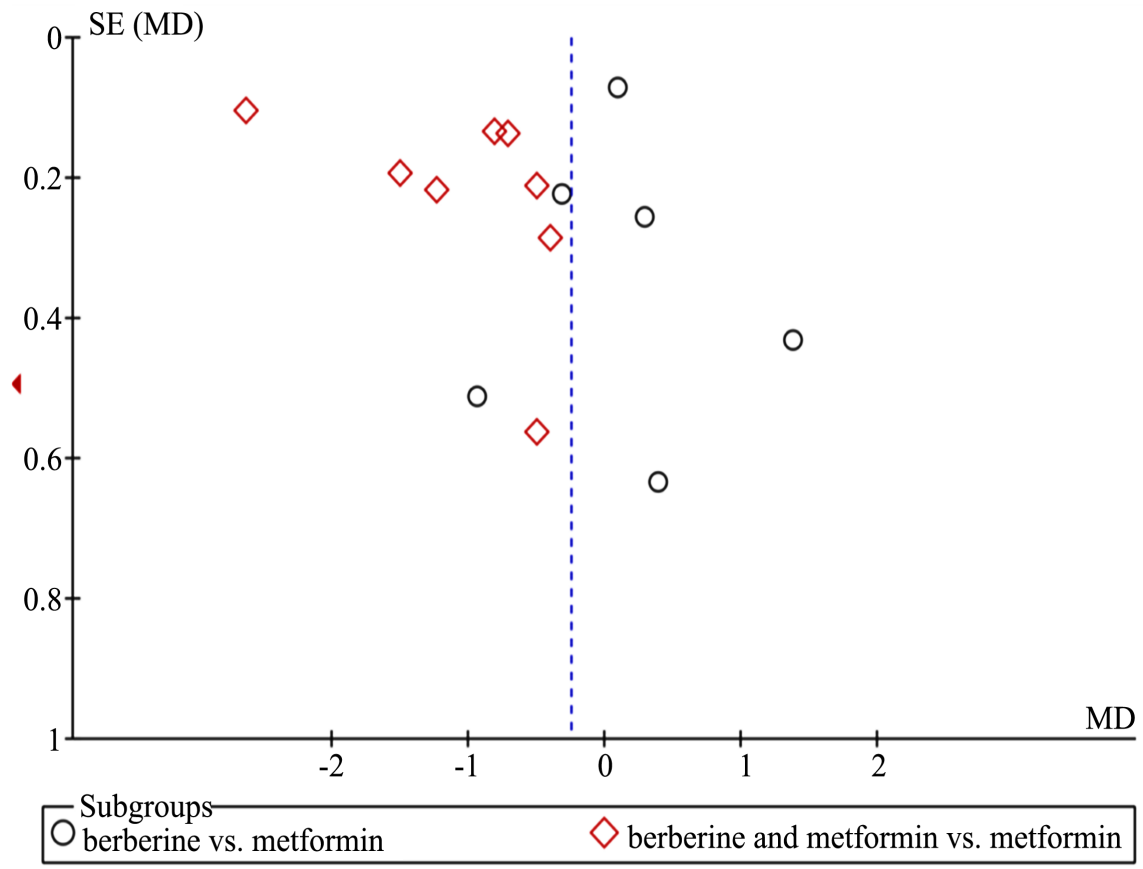

Figure 8. Funnel plot of outcome measure FPG. 
review. The study included several newly-published trials and preformed subgroup analysis. The results of our meta-analysis are similar to those of Chen WN and Lan JR [38] [39], regarding FPG, 2hPG and HbA1c. We added HOMA-IR to evaluate the hypoglycemic effects, and berberine combined with metformin also significantly reduced HOMA-IR. But the level of evidence was not high because of only one study included. We carried out the sensitivity analysis by eliminating literature one by one. After excluding the article, Cao Y [27], FPG and HbAlc for the subgroup of berberine vs. metformin changed from $[P=0.53, P=71 \%$, $M D=-0.13,95 \% \mathrm{CI}(-0.27,0.54)]$ and $[P=0.31, P=70 \%, M D=-0.17,95 \% \mathrm{CI}$ $(-0.49,0.16)]$ to $[P=0.89, P=50 \%, M D=-0.02,95 \% \mathrm{CI}(-0.33,0.29)]$ and $[P=$ $0.02, P^{2}=52 \%, M D=-0.29,95 \%$ CI $\left.(-0.53,-0.05)\right]$, respectively. It is different from the previous analysis.

\subsection{Limitations}

There are several limitations that should be considered before recommending the conclusion of this review for clinical practice. First, appropriate randomization is necessary to avoid selection bias. Nevertheless, random sequence generation and allocation concealment were not reported in detail in the included trials. Most trials only stated that participants were randomly assigned, but without further details. Second, all the trials did not apply blinding; therefore, nondouble-blinding may led to performance bias. Third, All the trials were conducted among Chinese participants in the mainland of China and they did not describle the study plan or publish a study protocol in advance; therefore, attrition bias and selective reporting bias might exist. Fourth, there was heterogeneity in the interventions, as can be seen from the primary characteristics of included trials. The optimal dose, optimal duration of berberine and metformin, even interactions between them requires further study. Finally, publication bias might exist in this review. Therefore all of the outcomes should be carefully interpreted based on substantial methodological and clinical diversity.

\subsection{Implications for Research}

This meta-analysis comprehensively quantified the efficacy and safety of berberine and metformin in the treatment of T2DM. Thirteen studies (fifteen trials) with 1173 participants were included. Although berberine plus metformin can remarkably improve blood sugar profiles, the evidence must be considered inconclusive. This is because the available studies had high heterogeneity and high risk of bias. Furthermore, the safety of the new drug, berberine, is unproven because of the lack of toxicological evidence, despite the fact that adverse events have been reported only rarely.

Further research should emphasize methodological quality, especially the methods of randomisation, allocation concealment, adequacy of blinding and sample size estimation, so that selection bias, performance bias, detection bias, attrition bias and reporting bias can be avoided. Moreover, registration of the trial protocol is essential to ensure reliability of trial results. Studies sample should be 
large with a long term follow-up to assess long term effects and safety of berberine and metformin. Finally, report strictly according to CONSORT [40] to improve the levels of evidence and clinical values.

\section{Conclusion}

The evidence from our meta-analysis suggests that berberine combined with metformin has a significant hypoglycemic effect and safety for T2DM. There is no obvious difference in hypoglycemia between berberine and metformin group. Due to the lack of high quality clinical trials, the efficacy of berberine alone or combined with metformin at treating T2DM remains to be validated. It needs to be further verified by high-quality, large sample size and multi-center RCTs.

\section{Funding}

This research was supported by a grant from the project of Administration of the Traditional Chinese Medicine of Guangdong Province of China (Grant No. 20191065).

\section{Conflicts of Interest}

None of the authors has any potential conflicts of interest associated with this research.

\section{References}

[1] Arslanian, S. (2002) Type 2 Diabetes in Children: Clinical Aspects and Risk Factors. Hormone Research in Paediatrics, 57, 19-28. https://doi.org/10.1159/000053308

[2] Guariguata, L., Witing, D.R., Hambleton, I., Beagley, J., Linnenkamp, U. and Shaw, J.E. (2014) Global Estimates of Diabetes Prevalence for 2013 and Projections for 2035. Diabetes Research and Clinical Practice, 103, 137-149. https://doi.org/10.1016/j.diabres.2013.11.002

[3] Chinese Diabetes Society (2021) Guideline for the Prevention and Treatment of Type 2 Diabetes Mellitus in China (2020 Edition) (Part 1). Chinese Journal of Practical Internal Medicine, 41, 668-695.

[4] Bailey, C.J. (2017) Metformin: Historical Overview. Diabetologia, 60, 1566-1576. https://doi.org/10.1007/s00125-017-4318-Z

[5] Duncan, L.I. and Clarke, B.F. (1965) Pharmacology and Mode of Action of the Hypoglycaemic Sulphonylureas and Diguanides. Annual Review of Pharmacology, 5, 151-162. https://doi.org/10.1146/annurev.pa.05.040165.001055

[6] Blonde, L., Dipp, S. and Cadena, D. (2018) Combination Glucose-Lowering Therapy Plans in T2DM: Case-Based Considerations. Advances in Therapy, 35, 939-965. https://doi.org/10.1007/s12325-018-0694-0

[7] Morales, D.R. and Morris, A.D. (2015) Metformin in Cancer Treatment and Prevention. Annual Review of Medicine, 66, 17-29. https://doi.org/10.1146/annurev-med-062613-093128

[8] Lamanna, C., Monami, M., Marchionni, N. and Mannucci, E. (2011) Effect of Metformin on Cardiovascular Events and Mortality: A Meta-Analysis of Randomized Clinical Trials. Diabetes, Obesity and Metabolism, 13, 221-228. 
https://doi.org/10.1111/j.1463-1326.2010.01349.x

[9] Bhat, A., Sebastiani, G. and Bhat, M. (2015) Systematic Review: Preventive and Therapeutic Applications of Metformin in Liver Disease. World Journal of Hepatology, 7, 1652-1659. https://doi.org/10.4254/wjh.v7.i12.1652

[10] Breining, P., Jensen, J.B., Sundelin, E.I., Gormsen, L.C., Jakobsen, S., Busk, M., et al. (2018) Metformin Targets Brown Adipose Tissue in Vivo and Reduces Oxygen Consumption in Vitro. Diabetes, Obesity and Metabolism, 20, 2264-2273. https://doi.org/10.1111/dom.13362

[11] Neven, E., Vervaet, B., Brand, K., Gottwald-Hostalek, U., Opdebeeck, B., De Maré, A., et al. (2018) Metformin Prevents the Development of Severe Chronic Kidney Disease and Its Associated Mineral and Bone Disorder. Kidney International, 94, 102-113. https://doi.org/10.1016/j.kint.2018.01.027

[12] Leng S.H., Lu, F.E. and Xu, L.J. (2004) Therapeutic Effects of Berberine in Impaired Glucose Tolerance Rats and Its Influence on Insulin Secretion. Acta Pharmaceutica Sinica, 25, 496-502.

[13] Kong, W., Wei, J., Abidi, P., Lin, M., Inaba, S., Li, C., et al. (2004) Berberine Is a Novel Cholesterollowering Drug Working through a Unique Mechanism Distinct from Statins. Nature Medicine, 10, 1344-1351. https://doi.org/10.1038/nm1135

[14] Lee, Y.S., Kim, W.S., Kim, K.H., Yoon, M.J., Cho, H.J., Shen, Y., et al. (2006) Berberine, a Natural Plant Product, Activates AMP-Activated Protein Kinase with Beneficial Metabolic Effects in Diabetic and Insulin-Resistant States. Diabetes, 55, 22562264. https://doi.org/10.2337/db06-0006

[15] Derosa, G., D’Angelo, A., Bonaventura, A., Bianchi, L., Romano, D. and Maffioli, P. (2013) Effects of Berberine on Lipid Profile in Subjects with Low Cardiovascular Risk. Expert Opinion on Biological Therapy, 13, 475-482. https://doi.org/10.1517/14712598.2013.776037

[16] Affuso, F., Mercurio, V., Fazio, V. and Fazio, S. (2010) Cardiovascular and Metabolic Effects of Berberine. World Journal of Cardiology, 2, 71-77.

https://doi.org/10.4330/wjc.v2.i4.71

[17] Lan, T., Shen, X., Liu, P., Liu, W., Xu, S., Xie, X., et al. (2010) Berberine Ameliorates Renal Injury in Diabetic C57BL/6 Mice: Involvement of Suppression of SphKS1P Signaling Pathway. Archives of Biochemistry and Biophysics, 502, 112-120. https://doi.org/10.1016/j.abb.2010.07.012

[18] Zhao, W., Xue, R., Zhou, Z.X., Kong, W.J. and Jiang, J.D. (2008) Reduction of Blood Lipid by Berberine in Hyperlipidemic Patients with Chronic Hepatitis or Liver Cirrhosis. Biomedicine \& Pharmacotherapy, 62, 730-731. https://doi.org/10.1016/j.biopha.2008.01.007

[19] Ren, T.T., Suo, L.X., Chen, X.O., Yang, W., Tang, M.M. and Li, X.Q. (2018) Curative Effect Analysis of Berberine and Probiotics in Improving Intestinal of Metformin. Chinese Journal of Modern Drug Application, 12, 1-4. https://doi.org/10.1080/17535654.2018.1469321

[20] Liu, J.P., Zhang, M., Wang, W.Y. and Grimsgaard, S. (2004) Chinese Herbal Medicine for Type 2 Diabetes Mellitus. Cochrane Database of Systematic Reviews, No. 3. Article No. CD003642. https://doi.org/10.1002/14651858.CD003642.pub2

[21] World Health Organization (1999) Definition, Diagnosis and Classification of Diabetes Mellitus and Its Complications: Report of a WHO Consultation. Part 1, Diagnosis and Classification of Diabetes Mellitus. World Health Organization, Geneva.

[22] Chinese Diabetes Society (2014) Guidelines for the Prevention and Treatment of 
Type 2 Diabetes in Chian (2013). Chinese Journal of Endocrinology and Metabolism, 30, 893-942.

[23] Higgins, J.P. and Green, S. Cochrane Handbook for Systematic Review of Interventions. Versin 5.1.0. http://www.cochrane-handbook.org

[24] Yin, J., Xing, H. and Ye, J. (2008) Efficacy of Berberine in Patients with Type 2 Diabetes. Metabolism, 57, 712-717. https://doi.org/10.1016/j.metabol.2008.01.013

[25] Xue, S.X., Xu, J.Q. and Zhan, L.L. (2012) Efficacy of Sulfonylureas Combined with Berberine and Metformin in Treatment of Diabetes Mellitus. Shaanxi Journal of Traditional Chinese Medicine, 33, 1335-1336.

[26] Zhang, Y.D. and Yuan, X. (2012) Clinical Observation of Berberine in the Treatment of Type 2 Diabetes. Journal of Heze Medical College, 24, 27-28.

[27] Zhang, H., Wei, J., Xue, R., Wu, J.-D., Zhao, W., Wang, Z.-Z., et al. (2010) Berberine Lowers Blood Glucose in Type 2 Diabetes Mellitus Patients through Increasing Insulin Receptor Expression. Metabolism, 59, 285-292.

https://doi.org/10.1016/j.metabol.2009.07.029

[28] Cao Y. (2007) Clinical Study of Multifactorial Intervention to Improve Insulin Resistance in Type 2 Diabetes Mellitus. Shandong Traditional Chinese Medicine University, Shandong.

[29] Li, M.L. (2008) Clinical Observation of Berberine Combined with Metformin in the Treatment of Type 2 Diabetes Mellitus. Hubei Journal of Traditional Chinese Medicine, 30, 34-35.

[30] Liu, Z.M. (2013) Effect of Metformin Combined with Berberine in the Treatment of Type 2 Diabetes Mellitus. Zhejiang Journal of Integrated Traditional Chinese and Western Medicine, 23, 380-382.

[31] Zhou, Q. and Huang, S.P. (2012) Clinical Study of Berberine Combined with Metformin in the Treatment of Obesity Type 2 Diabetes Mellitus. Journal of Practical Diabetology, 8, 33-35.

[32] Zhan, H.J., Chen, H.Y., Lin, C.X., et al. (2015) Effects of Berberine on T2DM and High Lipid Serum NO Level in Patients with Hyperlipidemin and the Activity of SOD. Journal of North Pharmacy, 12, 119-121.

[33] Lu, L.M., Zhang, L.P., Yin, Y.H., et al. (2013) Study on Thrapeutic Effect of Berberine Hydrochloride Combined with Metformin Treating Type 2 Diabetes Patients with Hyperlipidemia. World Chinese Medicine, 8, 1166-1168.

[34] Jiang, W.L. and Wang, H.R. (2019) Effects of Berberine Hydrochloride Tablets Combined with Metformin on Blood Glucose Control and Quality of in Patients with Type 2 Diabetes Mellitus. Chronic Pathematology Journal, 20, 1228-1232.

[35] Yang, X., Liu, Z.M. and Yang, H.J. (2020) Clinical Study on Berberine Hydrochloride Tablets Combined with Metformin in the Treatment of Primary Type 2 Diabetes. Shanghai Journal of Traditional Chinese Medicine, 54, 59-62.

[36] Dong, K.L., Shang, J.J. and Tao, L. (2017) Effect of Berberine Combined with Metformin on Serum Imflammatory Factors and Islet Function in Type 2 Diabetes Mellitus. Journal of Clinical and Pathological Research, 37, 1418-1422.

[37] Suhail, A.A., Iqbal, A.M., Tariq, Z.S., et al. (2017) Berberine Protects against Metformin-Associated Lactic Acidosis in Induced Diabetes Mellitus. Iranian Journal of Basic Medical Sciences, 20, 511-515.

[38] Chen, W.N., Duan, S.J., Zeng, L.N., et al. (2015) Berberine versus Metformin in Treatment of Type 2 Diabetes: A Systematic Review of Randomized Control Trials. Journal of Liaoning University of TCM, 17, 151-154. 
[39] Lan, J.R., Zhao, Y.Y., Dong, F.X., Yan, Z., Zheng, W., Fan, J., et al. (2015) MetaAnalysis of the Effect and Safety of Berberine in the Treatment of Type 2 Diabetes Mellitus, Hyperlipemia and Hypertension. Journal of Ethnopharmacology, 161, 69-81. https://doi.org/10.1016/j.jep.2014.09.049

[40] Bian, Z., Liu, B., Moher, D., Wu, T., Li, Y., Shang, H., et al. (2011) Consolidated Standards of Reporting Trials (CONSORT) for Traditional Chinese Medicine: Current Situation and Future Development. Frontiers of Medicine, 5, 171-177. https://doi.org/10.1007/s11684-011-0132-Z 